\title{
Bilateral congenital coronary artery fistula
}

\author{
A SCHNEEWEISS, S RATH, HN NEUFELD \\ From the Heart Institute, Chaim Sheba Medical Center, Tel Hashomer, Israel
}

Bilateral congenital coronary artery fistula may be defined as a condition in which more than one coronary artery gives rise to a fistulous tract. Twenty such cases have been reported. ${ }^{1-6}$ Only two of them were diagnosed angiocardiographically and corrected surgically. ${ }^{\circ}$ A case studied by selective coronary arteriography and operated upon successfully is presented here.

\section{Case report}

A 38-year-old man was admitted for investigation of precordial pain on exertion, of one year's duration, which had increased in the previous month. On admission the heart rate was 72 , blood pressure $160 / 100 \mathrm{mmHg}$, there were no signs of congestive heart failure, and findings on physical examination were normal. The electrocardiogram and thoracic radiograph were normal. Selective coronary arteriography demonstrated aneurysmal dilatation of the left anterior descending coronary artery at its origin, with complete obstruction distal to it. The distal segment of this artery was filled via a wide collateral vessel from the left circumflex artery which showed multiple narrowings. Multiple vessels appearing late after the injection filled a fistulous tract draining into the main pulmonary artery (fig 1).

The right coronary artery showed severe obstructive lesions, and filled, via multiple branches, a fistulous tract draining into the main pulmonary artery (fig 2). At operation, both fistulous tracts were ligated and aortocoronary bypass grafts to the left anterior descending, left circumflex, and right coronary arteries were inserted. The patient was released from hospital after an uneventful postoperative course of 21 days.

\section{Discussion}

Congenital coronary artery fistula may be defined as a communication of a long coronary artery with one of the atria or ventricles, the coronary sinus, superior vena cava, or the pulmonary trunk. It is an uncommon congenital cardiac lesion, about 400 cases having been reported ${ }^{7}$ since the first description by Krause in $1865 .{ }^{8}$ Its estimated incidence is $0.4 \%$ of the cases with congenital heart disease.

Reviewing 172 cases of congenital coronary artery fistula, McNamara and Gross $^{9}$ found four cases of Address for reprint requests: Professor HN Neufeld, Heart Institute, Chaim Sheba Medical Center, Tel Hashomer, Israel.

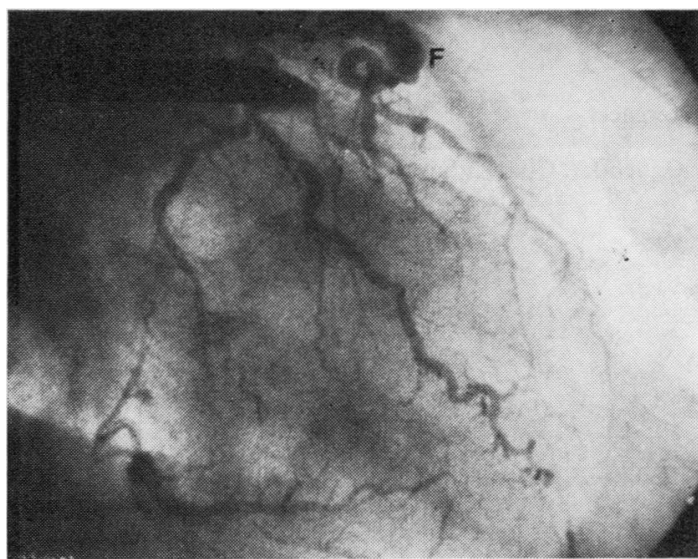

Fig 1 Selective left coronary arteriography in the right anterior oblique projection. The left anterior descending artery is completely occluded, and the circumflex artery shows obstructive lesions. Multiple vessels, appearing late, fill a fistulous tract $(F)$ which drains into the main pulmonary artery.

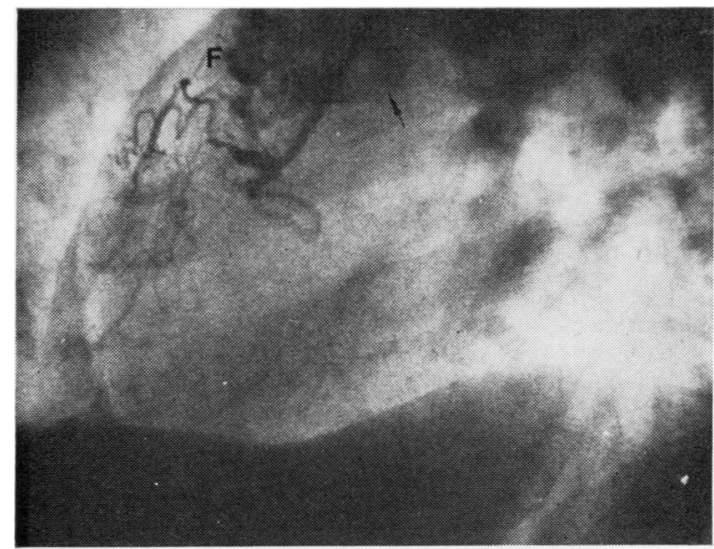

Fig 2 Selective right coronary arteriography in the left anterior oblique projection. The right coronary artery shows severe obstructive lesions, and fills via multiple branches a fistulous tract $(F)$ which drains into the main pulmonary artery (arrow). 
bilateral fistula, involving both coronary arteries. In 1968 Ogden $^{1}$ found 11 such cases. Another case was found at necropsy by Rose. ${ }^{4}$ Two other cases were diagnosed angiocardiographically but not corrected surgically. ${ }^{2} 3$ Two others were corrected surgically. ${ }^{6}$ In our case bilateral fistulae, involving tracts from the right and left coronary arteries were present, and were probably a contributing factor to the patient's chest pain. It is possible that the increased coronary flow predisposed to the relatively early development of severe coronary atherosclerosis in this patient. The fistulous tracts were ligated and the patient has remained asymptomatic for six months since. A similar case also diagnosed angiocardiographically and treated surgically was reported by Gupte et $a l^{5}$ in 1979.

\section{References}

Ogden JA. Congenital variations of the coronary arteries. A thesis. 1968, p 65.

${ }^{2}$ Reddy K, Gupta M, Hamby RI. Multiple coronary arteriosystemic fistulas. Am J Cardiol 1974;33:304-6.

${ }^{3} \mathrm{Babb}$ JD, Field JM. Double coronary arteriovenous $\frac{\rho}{\sigma}$ fistula. Chest 1977;72:656-8.

${ }^{4}$ Rose AG. Multiple coronary arterioventricular fistulae. @ Circulation 1978;58:178-80.

${ }^{5}$ Gupte SS, Ryan GF, Easley RM. Bilateral congenital $\overrightarrow{0}$ coronary artery-pulmonary artery fistulae. Report of two unusual cases. Angiology 1979;4:276-80.

${ }^{6}$ Iskandrian AS, Kimbris D, Bernis CE, Segal BL. Coronary artery to pulmonary artery fistula. Am Heart J 1978;96: 505-609.

7 Neufeld HN, Schneeweiss A. Coronary arterial anomalies in infants and children. To be published (1980).

${ }^{8}$ Krausse W. Über den ursprung einer accessorischen $\mathrm{A}$ Coronaria Cordia aus der A pulmonalis. $Z$ Rationelle Med 1865;24:225-40.

${ }^{9}$ McNamara JJ, Gross RE. Congenital artery fistula. $\rightarrow$ Surgery $1969 ; 65: 59-67$. 